\title{
Kebijakan Presiden Trump dan Respon Masyarakatnya terhadap Larangan Muslim Arab Tinggal di Amerika Serikat
}

\author{
Jawahir Thontowi \\ Fakultas Hukum Universitas Islam Indonesia Yogyakarta \\ Jln. Tamansiswa No. 158 Yogyakarta \\ impress_jawahir@yahoo.com
}

Received: 2 Oktober 2017; Accepted: 26 Desember 2017; Published: 28 Februari 2018

DOI: 10.20885/iustum.vol24.iss3.art2

\begin{abstract}
This research aimed to answer three problems: First, how is the Policy of President Trump related to banning on Muslim immigrants from living in the United States based on International Law and International human Right Law perspectives, and second, what are the responses and efforts of the US citizens related to condition of Muslim immigrants in the US. This research used normative legal research with library study. This study showe that: First, the policy of President Trump related to banning on Muslim immigrants has partly violated the international regulations and human rights, particularly UNHCR Convention 1951, ICCPR, and ICESCR 1966; Second, the responses of the US citizens are manifested in the forms of not only standing against the Policy of President Trump, but also fighting for the basic rights and freedom of Muslim immigrants by many lawyers, either by providing consultation and defense in court on a free basis, or by lobbying and negotiating with legislative institutions both at the state and federal government level.
\end{abstract}

Keywords: Muslim Immigrants and Refugees; Discrimination; Executive Order, President

\section{Abstrak}

Penelitian ini dilakukan dengan maksud dan tujuan untuk menjawab dua rumusan permasalahan, pertama, bagaimana kebijakan Presiden Trump terkait pelarangan imigran Muslim untuk tinggal di Amerika Serikat dari perspektif hukum dan HAM Internasional, dan kedua, bagaimana respon dan upaya masyarakat AS terhadap nasib imigran Muslim di AS. Metode penelitian yang digunakan adalah penelitian hukum normatif dengan studi pustaka. Adapun penelitian menyimpulkan sebagai berikut: pertama, kebijakan Presiden Trump terkait pembatasan imigran Muslim sebagian telah melanggar peraturan hukum dan HAM internasional, utamanya Konvensi UNHCR 1951, Kovenan ICCPR, dan Kovenan ICESCR 1966; kedua, respon masyarakat AS tidak saja ditujukan oleh sikap menentang kebijakan Presiden Trump, melainkan juga para pengacara telah memperjuangkan hak-hak dasar dan kebebasan para imigran Muslim baik dengan menyediakan konsultasi dan pembelaan di pengadilan secara cuma-cuma, maupun dengan melakukan lobi dan negosiasi terhadap lembaga legislatif di tingkat negara bagian dan pemerintahan federal.

Kata-kata Kunci: Imigran Muslim dan Pengungsi; Diskriminasi; Eksekutif Order, Presiden. 


\section{Pendahuluan}

Tidak menafikan jika ada kesangsian atas terpilihnya Donald Trump. Lebih menarik ketika Amerika Serikat (AS) sebagai negara pelopor demokrasi menjadi mundur ke belakang. Hillary Clinton yang hampir menang menjadi Presiden, tibatiba dibalikkan keadaan dengan memenangkan Trump dalam pemilihan.

Fakta politik internal AS, tercium aroma demokrasi tidak sehat. Hillary yang oleh sebagian Negara-negara Bagian diprediksi memenangkan pemilihan Presiden, justru harus menerima kekalahan yang cukup signifikan. Salah satu alasannya, beberapa kalangan masyarakat konservatif tidak menghendaki Presiden AS dipimpin seorang wanita. Tokoh-tokoh agama Protestan, Katolik tidak menyetujui adanya pemimpin wanita. Sebagaimana mereka juga tidak menyetujui seorang wanita menjadi pastor. Bahkan penolakan ini juga didukung oleh Paus Benediktus XVI. ${ }^{1}$

Isu tersebut menjadi menarik untuk di teliti dengan pendekatan ilmu hukum dan Hak Asasi Manusia (HAM) Internasional. Di satu pihak, topik ini merupakan isu aktual dan menarik dalam ranah ilmu hukum dan dan hak asasi manusian secara internasional. Pembatasan imigran muslim untuk tinggal di AS dalam kebijakan Presiden Donald Trump dipandang bertentangan dengan nilai-nilai kesederajatan di depan hukum dan hukum serta hak asasi manusia, yang selama ini dijunjung tinggi masyarakat AS.

Di pihak lain, isu imigran muslim sebagai akibat konflik politik dan bersenjata di Irak, Suriah dan juga Libya secara terbuka menciptakan beberapa negara melakukan intervensi. Akibatnya, Presiden Donald Trump mengeluarkan pelarangan imigran Muslim, mengingat fakta bahwa gelombang pengungsi dan pencari suaka politik dari Irak, Suriah, Sudan, Libya, Somalia, dan Yaman yang mewakili suku bangsa Arab dan Afrika.

\section{Rumusan Masalah}

Adapun rumusan masalahnya dalam penelitian ini memberikan jawaban atas pertanyaan sebagai berikut. Pertama, bagaimana kebijakan Presiden Donald Trump

\footnotetext{
1 Lihat dalam "Pope Benedict XVI forbids Catholics from voting for Hillary", dalam situs http://www.tmn.today/2016/10/pope-benedict-xvi-forbid-catholics-voting-hillary/ diakses pada 23 Maret 2017.
} 
terkait pelarangan dan pembatasan imigran dan pengungsi Muslim dari perspektif hukum dan HAM Internasional? dan kedua, bagaimana sikap masyarakat AS dan khususnya para pengacara terhadap nasib imigran Muslim, baik karena mereka berperkara di pengadilan maupun karena masih berada dalam proses penyelidikan dan penyidikan?

\section{Tujuan Penelitian}

Adapun maksud dan tujuan penelitian ini adalah pertama, untuk memahami secara komprehensif tentang alasan-alasan politis dan juridis tentang dikeluarkannya kebijakan pelarangan atau pembatasan terhadap Muslim asal Timur Tengah di AS sebagai upaya untuk menjelaskan ada tidaknya pelanggaran dari kebijakan pelarangan atau pembatasan imigran Muslim tersebut, baik terhadap kaidah-kaidah hukum HAM, khususnya Konvensi 1951 tentang Pengungsi. Kedua, untuk mengkaji sikap masyarakat AS, khususnya pengacara terhadap imigran Muslim, baik yang berperkara di pengadilan maupun yang masih dalam proses penyelidikan dan penyidikan.

\section{Metode Penelitian}

Penelitian ini memfokuskan pada obyek Kebijakan Presiden Donald Trump, terkait dengan perencanaan, penerapan larangan orang-orang Muslim tidak diperkenankan masuk dan tinggal di Amerika Serikat.

Adapun penelitian ini dilakukan dengan menggunakan metode penelitian hukum normatif dengan studi pustaka (library research), yaitu dengan menggunakan: (1) Bahan hukum primer yaitu mencari pemahaman secara yuridis dari berbagai peraturan hukum, baik Hukum Dasar AS, dan Peraturan Perundangundangan lainnya, Perintah Presiden (Executive Order) untuk dilaksanakan Kementerian terkait. Selain itu, juga menggunakan pendekatan sejarah untuk mengindentifikasi bagaimana proses imigran Muslim dapat berintegrasi sesama bangsa AS. (2) Bahan hukum primer kedua adalah menggunakan berbagai Konvensi Internasional, seperti International Convenant on Civil and Political Right (ICCPR), International Convenant on Economic, Social, and Cultural Rights (ICESCR) 1966, dan juga Statuta 1951 tentang United Nation Hight Cummissioner 
for refugees (UNHCR). Bahan primer kedua ini penting digunakan sebagai instrumen utama yang digunakan untuk mengukur, apakah kebijakan Presiden Trump berkesesuaian dengan Konstitusi AS, dan juga tidak bertentangan dengan berbagai prinsip dalam hukum dan HAM Internasional. Selain itu, (2) penelitian ini menggunakan bahan-bahan non-hukum, seperti pendekatan sejarah, dan juga data-data dan fakta-fakta yang ada di luar Hukum Dasar dan Konvensi internasional. Dengan maksud data-data yang digunakan tersebut dapat diuji kesesuaiannya atau validitasnya dengan norma-norma hukum dan HAM Internasional lainnya.

Selain ada bahan-bahan hukum primer dan bahan hukum sekunder dan tertier, juga bahan non-hukum, sebagai pelengkap yang digunakan sebagai data dan fakta yang dapat memperkuat argumentasi hukum, baik bersifat penolakan atau pernyataan yang memberikan dukungan. Adapun analisis yang digunakan untuk kebijakan Presiden Trump tersebut dilihat ada tidaknya kesesuaian antara peraturan hukum domestik atau hukum internasional, serta data dan fakta yang relevan lainnya. Terutama terkait dengan asal-usul umat Islam di AS, dan kontribusinya terhadap negara AS. Sedangkan analisis yang ditujukan pada kebijakan Trump tersebut menyimpang atau tidak, penelitian ini telah menggunakan pengelompokan penduduk Muslim di AS, (1) berdasarkan kepentingan mereka tinggal, (2) ada orang Muslim, yang sudah turun temurun sebagai pengusaha, (3) ada juga penduduk Muslim sebagai permanen residen karena memiliki kompetensi keahlian dalam bidang ilmu tertentu. Seberapa jauh kebijakan Presiden Trump tersebut diskriminatif, selain dilakukan analisis perbandingan terhadap norma-norma hukum Hukum Dasar AS, juga Konvensi HAM dan Konvensi UNHCR 1951.

\section{Hasil Penelitian dan Pembahasan}

\section{Islam Phobia di AS}

Muslim imigran datang ke AS sekitar abad ke 1700 hampir berbarengan dengan kedatangan budak-budak yang didatangkan. Namun, sejak 1965 akar pembatasan mulai dilakukan dengan tidak mengacu pada alasan agama dan asalusul kebangsaan. Imigran Muslim Timur Tengah, umumnya diterima karena 
kesempatan kerampilan kerja dan hubungan keluarga. Proses akulturasi imigran Muslim di AS telah terjadi melalui empat model yaitu, asimilasi, separasi, integrasi dan marjinalisasi.

Adapun perbedaan antara Muslim imigran dengan warga AS pada umumnya, karena perbedaan peradaban antara Muslim dengan Barat. Dari U.S Religious Lanscape, mencatat bahwa perbedaan identitas karena basis keagamaan ditemukan sangat signifikan. Penduduk AS mayoritas Kristen (72\%), sementara penduduk Muslim tergolong minoritas (0.6\%) menjadi salah satu faktor penyebab terhambatnya integrasi. Dasar keagamaan ini menimbulkan konsekuesni sosial dan politik serta ekonomi begitu komplek. Misalnya saja, setiap hari setiap Muslim wajib melaksanakan shalat lima waktu, yang dipandang aneh bagi warga AS bagi keberlangsungan kerja. Begitu juga larangan, makanan seperti daging dengan label halal, minuman khomr yang beralkohol, dan juga pergaulan bebas tidak menjadi persoalan bagi warga AS non-Muslim. Nilai-nilai keagamaan dalam keluarga dan masyarakat tidak kemudian menjadi faktor penghambat. Muslim memandang hubungan keluarga dan perkawinan sebagai hubungan yang suci atau sakral dan mengikat bagi keluarga Muslim. Tidak demikian halnya, bagi keluarga AS yang non-Muslim. Hal ini dapat menimbulkan persepsi yang salah ketika bagi Muslim hak-haknya secara aqidah dan ibadah harus diprioritaskan. ${ }^{2}$

Para imigram Muslim dari Timur Tengah dipandang berbeda dan agak asing bila dibandingkan dengan imigran Yahudi dalam masyarakat konservatif AS. Kendatipun imigran Muslim kurang begitu mulus dalam proses akulturasi dengan budaya dan lingkungan setempat, mengalami ketegangan, adaptasi dengan budaya setempat. Perubahan dramatis dipicu tragedi teror bom 11 September 2001. Sejak itulah, sentimen dan kebencian masyarakat AS terhadap terhadap imigran Muslim terus tumbuh dan menyebar luas.

Brandon Hwang dan Kyle Pang, menyimpulkan bahwa kesulitan proses integrasi dan asimilasi budaya antara Muslim imigran dari Timur Tengah ke budaya AS, didasarkan citra negatif yang dibesar-besarkan media. Sekelompok

${ }^{2}$ Jamil Al Wekhian, “Aculturation Process of Arab Muslim Immigrant in the United States”, Journal Asian Culture and History, Vol 8. Number 1. 2016, hlm. 94. 
masyarakat Kristen konserpatif memperlakukan diskriminasi karena kaum Muslim merupakan ancaman terhadap eksistensi, kepentingan dan keamanan Amerika. Meskipun proses asimilasi dan integrasi budaya Muslim imigran dipandang sebagai lingkaran syetan di AS, banyak cara dan jalan atau forum, baik yang formal maupun yang terstruktur untuk terjadinya proses integrasi dbydaya, seperti melalui pendidikan, membuat forum persahabatan sehingga nilai-nilai budaya Muslim juga dapat diterima kalangan masyarakat AS. ${ }^{3}$

Hal ini juga didukung oleh hasil kesimpulan Jamil Al-Wekhian proses ingtasi Muslim imigran di AS, telah dihambat oleh berbagai faktor yang begitu domain seperti, perbedaan latar belakang budaya dan agama, perbedaan nilai-nilai moral dan etika, persepsi tenang hubungan tentang jender, demokratisasi penduduk Arab di mass-media menjadi faktor penghambat keberhasilan integrasi di AS. ${ }^{4}$

Karena itu, citra positif terhadap imigran Muslim tidak mudah untuk dirubah. Beberapa pakar AS mencoba untuk meluruskan miskonsepsi terhadap Muslim melalui hasil-hasil penelitian ilmiah yang meragukan validitas tuduhan terhadap terorisme Al-Qaeda pimpinan Osama bin Laden. Menurut Susan Lindauer, sebagian pejabat AS mengetahui skenario tersebut. Lindauer juga merupakan orang yang memiliki kekayaan pengetahuan tentang perang intelijen, kerjasama investigasi hubungan antara Perang Irak dengan Teror Bom 11 September 2001 di AS. Mereka sesungguhnya mengetahui kebenaran pengetahuan intelijen merupakan fakta, tetapi tidak dapat mengubah pandangan sebagaimana putusan Konggres dan Gedung Putih terhadap masyarakat AS. ${ }^{5}$

Menurut David Ray Griffin dalam karyanya The 9/11 Commission Report: Omissions and Distortions menyimpulkan penolakan yang menegaskan kebenaran sangkaan; Pertama, fakta yang diterima menunjukkan enam orang pelaku pembajakan yang masih hidup, salah satunya Muhammad Albar sebagai seorang muslim saleh yang tidak memiliki kemampuan sebagai seorang teroris, begitu juga tidak mempunyai kemampuan menerbangkan pesawat sebagaimana disangkakan

\footnotetext{
${ }^{3}$ Brandon Kwang dan Kyle Pang, An Era of Islamaphobia: The Muslim Immigrant Experience in America, Pepperdine Journal of Communication Research, Vol. 5, Article 11, 2017, hlm. 53.

${ }^{4}$ Op. Cit., Jamil, Al Wekhian, hlm. 96.

${ }_{5}^{5}$ Susan Lindauer, Extreme Prejudice: The Terrifying Story of the Patriot Act and the Cover Ups of 9/11 and Iraq, Create Space Independent Publishing Platform, 2010, hlm. 17-18.
} 
oleh Komisi itu sendiri. Kedua, Komisi juga telah menggolkan teori kontradiktif terkait bangunan WTC. Tidak pernah terjadi ada api yang dapat meruntukan besi baja yang kokoh, hanya karena dampak api dari pesawat terbang yang ditabrakkan.

Menurut pengakuan Lavva Silver Steins, bahwa bangunan itu runtuh dan dilakukan dengan suatu penghancuran terkendali (this building was brought down by controlled demolition). Pengakuan di atas, fakta runtuhnya gedung WTC ditelaah oleh sepuluh teori yang konsisten satu sama lain tidak mendukung. Kesimpulan David Ray menegaskan bahwa "I have learned from the commission and distortions discuss here, that the commission final report simple cannot be trusted". ${ }^{6}$

Kendatipun banyak keraguan tentang kebenaran apakah pesawat terbang yang menabrak gedung kembar benar atau tidak. ${ }^{7}$ Saat ini seakan-akan kasus tersebut menjadi tabu untuk dibicarakan di Amerika Serikat. Kebencian warga negara AS terhadap imigran Islam terus bergulir dari waktu ke waktu.

Tulisan-tulisan sarkastik seperti Islam identik dengan kekerasan, Islam agama tidak damai, Islam dikembangkan dengan menebar permusuhan, dan masih banyak lagi berbagai ekspresi kebencian terhadap Islam. Karenanya, tidak mudah untuk memupus citra buruk umat Islam di belahan negara-negara barat (Inggris, Perancis, Jerman, Australia, dan lainnya) termasuk di Amerika Serikat. ${ }^{8}$

Di tengah kecenderungan masyarakat barat anti-Islam tersebut, sangat mencengangkan ketika masyarakat barat tertarik untuk mendalami dan memahami Islam. Kajian-kajian Islam di berbagai perguruan tinggi dan lembagalembaga telah jadi perhatian serius. Tidak sedikit dari mereka memeluk agama Islam dengan mengucapkan dua kalimat syahadat. Hasil riset Pew Research Center menyebutkan sebanyak 3,3 juta umat Muslim (1\% dari jumlah total penduduk AS), hlm. 27.

${ }^{6}$ David Ray Griffin, The 9/11 Commission Report: Omissions And Distortions, Olive Branch Publishers, 2004,

${ }^{7}$ Keraguan tersebut muncul dari ilmuwan-ilmuwan AS baik para ahli teknik bangunan maupun profesor development. Mereka percaya bahwa runtuhnya gedung tersebut, telah direncanakan secara rahasia dengan menggunakan metode penghancuran gedung secara sadis. Dan Gedung kembar itu bisa runtuh ditabrak pesawat terbang yang kekuatan tidak seimbang dengan kokohnya gedung tersebut.

8 Perancis tergolong negara cukup demokratis dan toleran. Namun, sejak teror bom moncul di Perancis, maka Perancis dalam membuat kebijakan membatasi aktifitas umat Islam. Larangan perempuan berjilbab atau bercadar merupakan kebijakan rasis dan diskriminatif. 
diperkirakan akan terus meningkat untuk memeluk agama Islam, dan menurut hasil penelitian tersebut pada 2050 diprediksi akan mencapai 8,1 juta jiwa. ${ }^{9}$

\section{Imigran Muslim Stakeholder AS}

Bagaimanapun harapan imigran Muslim dari Timur Tengah, sebagai stakeholder warga AS ke depan terlihat optimistik. Pertama, bahwa sikap diskriminatif masyarakat AS, khususnya persepsi ini berkembang di kalangan warga Kristen AS yang konserpatif tampak semakin kuat. Namun, sikap diskriminatif itu jauh lebih berat dirasakan oleh generasi Muslim yang sudah tua umurnya. Sementara, di kalangan generasi muda Muslim saat ini, proses integrasi telah berlangsung dengan baik, utamanya sebelum ada persitiwa 11 September 2001. Kedua, produk diskriminasi yang muncul sejak 11 September tersebut, telah menciptakan karakter identitas terpisah antara Muslim dengan warga Amerika secara keseluruhan. Sebagian kelompok Muslim yang terpisah merasakana adanya identitas ganda, baik karena latar belakang sejarah, suasana sosial politik, dan geografis dan perasaan lemah, maupun karena perasaan sebagai akibat media global tentang provokasi terorisme bom. Ketiga, sesungguhnya, identitas budaya Muslim Arab dapat dibedakan ke dalam dua kelompok. Pertama, kelompok budaya tinggi (high cultutral identity) dan menengah (moderate cultural identity). Hight cultural Muslim idendity adalah orang imigran muslim yang umumnya sudah tua, yang bertahan dengan nilai-nilai budaya aslinya sehingga sulit untuk berasimilasi. Sedangkan kedua, kelompok Muslim dengan identitas budaya moderat, mereka adalah orang-orang Muslim dari Timur Tengah, yang mengalami proses asimilasi yang tertekan, karena mereka hidup tanpa dukungan pihak keluarga. Dengan tiadanya dukungan keluarga, maka pemuda-pemuda Muslim akan mengalami proses integrasi yang jauh lebih baik dengan warga AS. ${ }^{10}$

Kendatipun penduduk muslim di AS tergolong minoritas, secara kualitatif angka kehidupan mereka tergolong penduduk kelas menengah yang menjanjikan. sebagai stakeholder, warga AS berkesan bahwa Muslim kumuh atau miskin tidak

9 Lihat Besheer Mohamed, “A New Estimate Of The U.S. Muslim Population”, dalam http://www.pewresearch.org/fact-tank/2016/01/06/a-new-estimate-of-the-u-s-muslim-population/ diakses pada 23 Maret 2017.

${ }^{10}$ Op. Cit., Brandon Hwang dan Kyle Pang, hlm. 54. 
berpendidikan justru menandingi penduduk non-Muslim yang ada di AS. Pertama, sejak 2002 penduduk Muslim tergolong penduduk yang berpenghasilan menengah ke atas. Adapun rincian pendapatan menengah antara US\$50.000 s/d US\$ 75.000 (18\%), pendapatan tinggi dikisaran US\$ 75.000 s/d US\$ 100.000 (18\%). Dan tergolong berpendapatan tinggi US\$ $100.000 \mathrm{~s} / \mathrm{d}$ US\$ 150.000 (14\%), US\$ $150.000 \mathrm{~s} / \mathrm{d}$ US\$ 250.000 (12\%) mereka ini yang berpendapatan sangat tinggi sebagai pengusaha.

Kondisi ekonomi kaum Muslim yang sejahtera dan makmur tersebut tidak lepas dari latar belakang pendidikan yang lebih baik dibandingkan penduduk AS. Penelitian Cornel University sebagian terbesar (77,9\%) penduduk Muslim mengenyam pendidikan tinggi atau universitas. Hanya sekitar $24 \%$ penduduk Muslim yang tidak mengenyam pendidikan tinggi.

Penduduk Muslim menempati jabatan pekerjaan profesional yang menjanjikan. Pekerjaan mereka terbanyak bekerja di wilayah teknologi mesin (12\%)-(10,4\%), manajer perusahan (6,44\%), IT programmer $(7 \%)$, pembuatan rumah (10\%). ${ }^{11}$ Lebih menarik lagi terdapat beberapa penduduk Muslim di AS ada yang menduduki jabatan politis spektakuler seperti C. Jack Eliss, pernah menjadi walikota Macon, Georgia. Keith Ellison dan Andre Carson menjadi anggota Konggres AS.

Bahkan dalam catatan Daniel Pipes, tidak kurang dari 3.500 personil tentara AS beragama Islam. Kolonel Douglas Burpee, memperoleh pangkat Kolonel Angkatan Laut. ${ }^{12}$ Prestasi yang mereka peroleh juga karena kebijakan Pemerintah yang berorientasi pada meritokrasi. Sehingga siapa saja penduduk AS yang berprestasi dapat penghargaan atau reward yang sebanding dengan kualitas dan kemampuannya. Perlakuan negara terhadap para tentara Muslim diberikan tandatanda khusus keagamaan dalam pakaian seragamnya. Tanda untuk tentara Muslim berupa bulan sabit, sedang untuk Kristen, Katolik, dan Yahudi diberi tanda yang lain. Penandaan keagamaain ini salah satu tujuannya adalah untuk memberikan

\footnotetext{
11 http://www.allied.media.com diakses pada tanggal 23 Maret 2017

${ }^{12}$ Lihat Justin O Smith, The Muslim U.S. Military Experience, dalam www.danielpipes.org/comments/197390 diakses pada tanggal 27 Maret 2017
} 
kemudahan, memberikan pelayanan atau penghormatan pada saat mereka meninggal dunia. ${ }^{13}$

Banyak kaum Muslim yang telah memilih AS sebagai tempat dan tanah air mereka. Bukan karena mereka datang ke AS semata-mata untuk mencari pekerjaan, melainkan sebagai stakeholder di AS mereka menjadi penduduk yang turut pula berkontribusi pada AS sebagaimana mereka membuktikan dirinya memiliki semangat nasionalisme sebagai warga negara AS.

\section{Kebijakan Pembatasan Muslim Tinggal di AS}

Sejak Donald Trump dilantik menjadi Presiden AS, sikap anti-Islam tersebut semakin terasa nyata. Kebijakan politik luar negerinya menimbulkan ancaman bagi hubungan harmonis dengan negara-negara tetangga, khususnya negara Muslim. Ada sekitar 7 negara seperti Irak, Iran, Sudan, Suriah, Libia, Somalia, dan Yaman mewakili suku bangsa Arab dan Afrika yang di tolak masuk ke AS.

Alasan penolakan ini, karena kehadiran Muslim di AS dapat mengancam keamanan dan kedamaian warga AS. Tidak sedikit dari kelompok imigran tersebut diduga anggota ISIS (Islamic State of Iraq and Syria) menyusup ke AS sebagai pencari suaka politik atau pengungsi internasional. ${ }^{14}$ Tidak sedikit keluarga anggota keluarga Muslim dari Timur Tengah di AS mendadak ditolak masyarakat AS, khususnya kelompok Partai Republik yang konservatif. Padahal, kekerasan dan peperangan tetap terjadi di berbagai belahan dunia tidak selalu berkaitan dengan agama. Perang Dunia I dan II, yang dipelopori Negara-negara Eropa, baik kejahatan genosida sebagaimana dilakukan NAZI pimpinan Adolf Hitler di Jerman, Fasisme di Italia, dan Komunisme di Soviet Rusia merupakan bukti nyata agama tidak selalu menjadi faktor timbulnya kekerasan.

Sebagaimana Graham E. Fuller dalam karyanya menilai: "If we think that religion has been negative force in modern world history, consider the alaternative. Religion couldn't ave done worse than history of savage secular violence and unprecedented butchery

${ }^{13}$ Emerson William, Encyclopedia of United States Army in Sign an Uniforms, University of Oklahoma Press, 1996, hlm. 56-58.

${ }^{14}$ Lihat dalam laporan Homeland Security Committee, Syrian Refugee Flows. Security Risk and Counterterrorism Challenges. Preliminary Findings of a House Homeland Security Committee Review, November, 2015, hlm. 5. 
that determnated the history of the West in the twenties century, marked by two world wars, facism, Nazism, and communism,-- non of which had anything to do with religion." 15

Moslem Ban Policy atau kebijakan larangan muslim tersebut menimbulkan pro-kontra dalam politik AS. Sebagian besar warga AS khususnya mahasiswa menolak kebijakan Presiden mengingat hal tersebut dapat menimbulkan ketegangan dan permasalahan di dalam internal negeri.

\section{Kebijakan Presiden Trump dan Pelanggaran HAM terhadap Imigran Muslim}

Pada negara-negara yang menganut demokrasi liberal, baik di Eropa maupun di Amerika Serikat, pelanggaran HAM relatif kecil dibandingkan negara-negara yang menganut model autoritarianisme atau non-democratic countries. Sebagaimana di Turki, perlakuan negara yang menyimpang terhadap warga negara karena negara melarang kehadiran partai politik tertentu. ${ }^{16}$ Sama halnya dengan yang terjadi di negara-negara Asia Tenggara. Sudah berabad-abad minoritas Muslim Rohingnya tinggal di Myanmar, tetapi mereka tidak dapat diakui sebagai warga negara. Tetapi, mereka berstatus sebagai pendatang haram atau illegal migrant. ${ }^{17}$

AS sebagai negara termoderen penjunjung tinggi HAM, justru membuat contoh yang buruk. Donald Trump menjanjikan kepada pendukungnya dalam suatu kampanye untuk melarang imigran dari Timur Tengah masuk ke AS, mengingat telah mengancam keamanan dalam negeri (security homeland) AS. Trump menyatakan ambisinya bahwa "our country cannot be the victims of horrendous attacks by people that believe only in Jihad, and have no sense of reason or respect for human life. If I win the election for President, we are going to Make America Great Again." 18

Karena hal tersebut merupakan janji selama kampanye, kehendak untuk merealisasikan rencana semakin nyata ketika dia baru saja dilantik sebagai Presiden AS. Jajak pendapat (polling) telah merupakan dasar kebijakan pelarangan

\footnotetext{
hlm. 304.

${ }^{15}$ Graham E. Fuller, A World Without Islam, New York Boston London: Little, Brown and Company, 2010,

${ }^{16}$ Sedikitnya 11 Partai Politik aktif dan 8 Partai Politik tidak aktif, menurut hukum yang berlaku di Republik Turki merupakan Partai Politik terlarang. Beberapa alasan menyatakan bahwa mereka berkaitan dengan tindakan terorisme dan memiliki hubungan dengan organisasi terorisme. Lihat dalam https://en.wikipedia.org/wiki/List_of_illegal_political_parties_in_Turkey diakses pada 23 Maret 2017.

17 Lihat Jawahir Thontowi, Terorisme Negara. Kerjasama Konspiratif Menjinakean Islam Fundamentalis, Yogyakarta: UII Press, 2013, hlm. 171.

18 Lihat pernyataan Presiden Trump dalam https://www.donaldjtrump.com/press-releases/donald-j.trump-statement-on-preventing-muslim-immigration diakses pada tanggal 23 Maret 2018
} 
Muslim imigran. Namun, ternyata respon publik telah berlawanan, sehingga demo besar-besaran di berbagai Negara-negara Bagian turut menolaknya. Partai Republik yang pendukungnya tergolong rasis dan diskriminatif terhadap suku bangsa lain, khususnya Negara-negara Muslim.

-- Donald J. Trump is calling for a total and complete shutdown of Muslims entering the United States until our country's representatives can figure out what is going on. Most recently, a poll from the Center for Security Policy released data showing "25\% of those polled agreed that violence against Americans here in the United States is justified as a part of the global jihad" and 51\% of those polled, "agreed that Muslims in America should have the choice of being governed according to Shariah." (New York, NY, December 7th, 2015).

Konsep Syariah yang selama ini dipahami responden adalah terjadi karena missunderstanding atau miskonsepsi. Penyebutan konsep Syariah dipahami sebagai perbuatan yang menunjukkan kekerasan atau radikalisme. Perang atau jihad adalah tidak tepat. Hanya sebahagian benar jika rujukannya adalah opini yang dikembangkan Taliban di Afghanistan. Syariah identik dengan hukum qishas (hukuman mati), qadfa (hukuman zina), dan hukuman tazir lainnya. Padahal, konsep Syariah adalah jalan atau pedoman tentang seluruh aspek kehidupan manusia, di dalamnya mencakup aqidah (keyakinan), ibadah (menuju Allah SWT), muamalah (aspek sosial, ekonomi, politik dan pertahanan), dan akhlaqul karimah yang didasarkan pada Al-Qur'an dan Sunnah.

Bilamana kebijakan pelarangan terbatas pada kaum pendatang Muslim (immigrant Muslim), disebabkan oleh ancaman kaum Muslim yang mau menerapkan Syariat Islam, maka jelas Presiden Trump keliru dalam menggunakan argumentasi. ${ }^{19}$

Faktanya, ketika kebijakan hendak diterapkan ternyata mendapatkan perlawanan dari masyarakat Muslim, dan masyarakat AS pada umumnya. Salah satu sebabnya perlawanan itu timbul karena kebijakan diskriminasi tersebut dipandang telah melanggar hak-hak dasar dan hak-hak kebebasan manusia.

Berbagai kajian telah dilakukan di berbagai kampus. Termasuk Tim kajian mahasiswa Harvard Law School, Harvard Immigration and Refugee Clinical Program,

${ }^{19}$ Lihat Jawahir Thontowi, "The Islamic Perspective of the War on Terrorism and Current Indonesian Responses", Makalah Seminar Internasional the Human Rights 2003: The Year in Review diselenggarakan oleh the Castan Centre for Human Rights Law, Monash Law School, 2003, hlm. 8. 
terkait kebijakan Presiden Trump tentang Executive Order, khususnya bagi Pencari Suaka politik telah melanggar pelanggaran konstitusi dan hak asasi manusia.

Pertama, pelanggaran terhadap penahanan terhadap para pencari suaka politik, yang jelas Pemerintah Amerika telah melanggar kewajiban hukum internasional. Khususnya Pasal 31 ayat (2) Konvensi Pengungsi 1951: "states that a country may restrict the movement of refugee only when necessary". Menahan pencari suaka politik berdasarkan kepada undang-undang keimigratio nasional jelas bertentangan dengan Pasal 31 tersebut. Begitu juga, pelanggaran telah terjadi karena para pencari suaka politik telah mengalami kesulitan untuk melakukan konsultasi hukum dengan para pengacaranya. Padahal, umumnya jika mereka diberi kesempatan untuk membela diri maka mereka berpeluang untuk dibebaskan.

Kedua, pelanggaran karena perlakuan diskriminasi terhadap para pencari suaka politik dan pengungsi akibat berbeda agama dan asal usul kebangsaan. Tindakan diskriminatif tersebut jelas melanggar ketentuan hukum nasonal dan internasional. Hak untuk mendapatkan perlakuan yang sama di depan hukum, merupakan hak yang wajib diutamakan dalam konstitusi suatu negara. Termasuk kedudukan para pengjngsi, atai imigran Muslim dari Timur Pengah atau manapun untuk diperlakukan sama di AS.

Ketiga, pelanggaran pemerintah AS terhadap imigran Muslim karena telah melakukan deportasi dan pengembalian para pengungsi atau pencari suaka politik tanpa adanya hak untuk melakukan upaya hukum banding. Hal ini bertentangan dengan Pasal 3 ayat (2) UNHCR Convention 1951, dan juga bertentangan dengan ICCPR Pasal 26, American Covenant on Human Rights Pasal 24, dan ICESCR Pasal 2 ayat (2).

Keempat, pelanggaran dalam hal mengembalikan para pencari suaka politik, ke Meksiko negeri asalnya, yang sesungguhnya bertentangan dengan Prinsip NonRefoulment. Prinsip ini diatur dalam Pasal 33 dari Konvensi Pengungsi 1951, berbunyi sebagai berikut: "No contrancting State shall expel or return (refouler) a refugee in any manner whatsoever to the frontier of territorie where his life or freedom woulf 
be threatened an account of his reace, religion, nationality, membership o particular social group or political opinion." 20

Kelima, pelanggaran karena penolakan terhadap penyatuan kembali keluarga (family reunification) untuk sama-sama tinggal di AS. Banyak keluarga dari AS, dimana anak-anaknya atau keluarga karena terindikasi sebagai tersangka teroris tidak dapat masuk kembali ke AS, kendatipun sudah dijamin oleh orang tua yang telah tinggal lama di AS.

Selain itu, juga beberapa hal lain misalnya, penundaan dalam proses pengadilan, baik dilakukan terhadap para imigran Muslim maupun terhadap orang-orang yang diduga terlibat dalam gerakan teroris di AS. Kriminalisasi terhadap pencari suaka politik padahal tidak memiliki dasar hukum, khususnya bukti-bukti yang cukup dan memuaskan.

Hasil kajian tersebut, selain menunjukkan kepedulian mahasiswa kampus terhadap kebijakan Presiden Trump, juga pelanggaran HAM terhadap siapapun termasuk imigran Muslim akan ada saja pihak yang peduli untuk membela dan memberi bantuan.

\section{Mengamankan Kebijakan Presiden Trump}

Sebagai upaya mencegah warga negara AS dari ancaman dan serangan teroris, dan kekerasan lainnya, serta mencegah timbulnya kerugian hak-hak konstitusional warga negara AS. Kata-kata yang diucapkan Presiden Trump sangat jelas dan tidak mudah ditepis maknanya kecuali sikap diskriminatif. President Donald Trump "is calling for a total and complete shutdown of Muslims entering the United States." Presiden mengajak secara menyeluruh untuk melarang orang-orang luar masuk ke AS". Jika pelarangan diterapkan, tentu akan merugikan Pemerintah AS. Banyak imigran dari Negara-negara Muslim termasuk warga Indonesia yang dimungkinkan masuk ke AS untuk urusan perdagangan, pendidikan, kebudayaan dan kerjasama lainnya tentu harus dikecualikan.

\footnotetext{
${ }^{20}$ Lihat, kajian Tim Mahasiswa Harvard Law School, Harvard Immigration and Refugee Clinical Program, The Impact of President Trump's Executive Order on Asylum Seeker, hlm. 2-9.
} 


\section{Memorandum untuk Presiden}

Agar Presiden tidak melanggar Konstitusi AS, maka diterbitkan suatu perintah eksekutif dari Gedung Putih (The White House) melalui "Memorandun for the President". Isinya memerintahkan Presiden untuk memenuhi janji-janji dalam kampanyenya. Larangan tersebut didasarkan pada argumen bahwa, imigran AS keturunan asing melakukan serangan teroris di AS.

Tidak kurang dari 380 orang yang lahir berkebangsaan asing dipenjarakan karena terlibat terorisme. Kekhawatiran tersebut, bukan syarat bahwa perang melawan teroris harus menjadi prioritas, tetapi karena mereka memiliki kemampuan menerobos layar-layar screening. Ancaman bahaya juga timbul karena mereka melakukan perekrutan dan menciptakan radikalisasi pada warga Muslim yang lain. Tidak kurang dari 11 juta visa yang umumnya diterbitkan untuk warga negara, kini hanya terpenuhi 6 juta pertahun.

Sebagai upaya memenuhi janji-janji Presiden Trump dalam kampanye terkait undang-undang imigrasi. Sekaligus untuk menerapkan langkah-langkah kongkrit yang mengamanatkan kondisi keamanan AS.

1. Penundaan penerbitan visa terhadap negara-negara yang jika terjadi kelalaian pengidentifikasian screening tidak akan timbul suatu peristiwa apapun;

2. Mengimplementasikan sistem screening seragam keseluruhan program keimigrasian. Siapapun yang datang ke AS dapat menjamin rasa aman keselamatan dan keamanan nasional AS;

3. Penundaan program penerimaan pengungsi internasional selama 120 hari, untuk menenetukan pengungsi internasional manakah yang jika diterima memiliki resiko kecil untuk kepentingan nasional di AS;

4. Melakukan pencatatan administrasi secara sempurna tentang sistem pengeluaran dan pemasukan biometrik;

5. Untuk memperoleh visa, pelamar harus diwawancarai sebelum disetujui permohonannya; dan

6. Melakukan pengawasan terhadap keabsahan visa dalam periode tertentu sesuai dengan hukum yang berlaku. ${ }^{21}$

Kebijakan Presiden terkait dengan pembatasan warga negara AS keturunan asing, maka diperintahkan untuk melakukan beberapa langkah. Pertama, Pemerintah AS harus menjamin bahwa penerimaan terhadap pelamar ke AS tidak menabur sikap permusuhan terhadap negara dan terhadap prinsip-prinsip dasar

${ }^{21}$ Lihat Memorandum for The President dalam Dokumen resmi, The White House, Washington, 23 Januari 2017. 
negara AS. Kebijakan Presiden yang dilakukan adalah dengan mewajibkan; (a) mengutamakan perlindungan terhadap warga negara AS daripada warga negara keturunan asing yang akan melakukan serangan teoris di AS, (b) wajib mencegah penerimaan warga negara keturunan asing yang hendak melakukan penyalahgunaan peraturan perundang-undangan terkait keimigrasian untuk tujuan tidak terpuji. ${ }^{22}$

Kedua, kebijakan pelarangan masuknya imigran asing itu juga dimaksudkan untuk memberikan pengampunan terhadap individu-individu sebagai tersangka, yang bermaksud datang ke AS sebagai anak dan orang tua yang tinggal di AS, baik karena hubungan keluarga atau sebagai penduduk yang statusnya permanent resident. ${ }^{23}$ Upaya peningkatan pembatasan izin masuk juga dimaksudkan agar Pemerintah AS tidak terjebak pada kebijakan pelarangan masuk tersebut. Padahal, orang-orang Muslim yang orang tuanya tinggal di AS atau karena orang tuanya berstatus sebagai permanent resident harus dikecualikan dari pembatasan tersebut.

Selain itu, pembatasan tersebut erat kaiatannya dengan upaya melindungi para pekerja AS dengan memperkuat Integritas program pengeluaran visa kerja bagi orang-orang asing. Sebagai jaminan atas para pembayar pajak dari negaranegara asing yang datang ke AS, sebagai orang-orang yang dapat memenuhi kebutuhannya sendiri (self sulficy).

\section{Pengungsi Internasional ke AS}

Pengungsi internasional yaitu gelombang orang-orang yang melakukan perpindahan dari suatu negara menyeberang ke negara lain, untuk memperoleh perlindungan atau penyelamatan diri dari ancaman penderitaan yang luar biasa (well-prosecuted) karena adanya bencana kemanusiaan (perang) atau kekacauan oleh Pemerintah yang otoriter, sehingga tidak mungkin mereka tinggal di negaranya.

Tidak kurang sebanyak 752.154 orang-orang asing ilegal (illegal aliens) yang tergolong ke dalam pengungsi internasional atau pencari suaka politik (political

${ }^{22}$ Lihat Executive Order. The White House Washington. Protecting the Nation From Terrorist Attacks by Foreign Nationals, 23 Januari 2017.

${ }^{23}$ Disrection to Individuals Who Came to the United States as Children (DACA) and Exercising Posecitorial Discretion with respect to Individual who Are the Parents of U.S. Citizens or Permanent Residents (DAPA). 
asylum seeker) tertunda proses penetapannya. Sebagai negara peserta Konvensi 1951 United Nations on High Commissioner for Refugee, AS tergolong negara yang wajib menerima kehadiran pengungsi internasional sebagai wujud bantuan kemanusiaan (humanitarian asistance). Terdapat 2 tahapan yang harus dilaksanakan oleh negara pihak. Pertama, pengungsi yang masuk ke suatu negara tanpa dokumen lengkap mereka tidak akan dikenakan hukuman, selama mereka secepatcepatnya melaporkan diri kepada pihak-pihak berwenang setempat.

Kedua, adanya larangan bagi negara pihak untuk mengembalikan pengungsi atau mereka yang mengklaim dirinya sebagai pencari suaka ke negara asal secara paksa. ${ }^{24}$ Tahapan kedua diatas dalam Konvensi 1951 dikenal sebagai Prinsip Nonrefoulment, tercantum dalam Pasal 33 yang sifatnya dapat diberlakukan tanpa melihat apakah orang asing yang masuk ke negara penerima tersebut secara sah dan memenuhi persyaratan formal, bahkan jika orang asing itu masuk secara tidak sah.

Kesediaan AS menerima pengungsi bukan sekedar kewajiban moral dan hukum internasional. Lebih penting dari itu, karena Pemerintah AS dapat memberikan jaminan secara sosial, ekonomi dan politik. Negara AS dipandang sebagai negara bersistem pemerintahan demokratis dan menjunjung tinggi HAM. Sehingga kehadiran para pengungsi dapat diperlakukan secara sederajat (equality before the law), tidak diperlakukan secara diskriminatif (non-discrimination) secara suku, agama, ras, budaya dan jender. ${ }^{25}$ Kebijakan pembatasan tersebut bisa juga menjadi argumentasi atas timbulnya ancaman rasa aman dan damai secara nasional. Sehingga tindakan pemerintah yang berlebihan dapat dicegah dan tetap konstitusional. The detention of unlawful immigrates refugees and asylum seeker has emerged as a contemporary issue. States and face with an increasingly heavy administration task of responding to the claims of asylum from Iraq, Afganistan, Somalia, Sudan, that is from the areas in which human right area most at risk.

Jika ada suatu tindakan dilakukan aparat penegak hukum khususnya dari pengadilan administrasi, maka haruslah dilakukan peninjauan sebagamana halnya

\footnotetext{
24 Wagiman, Hukum Pengungsi Internasional, Sinar Grafika, Jakarta, 2012, hlm. 76-77.

${ }^{25}$ Lihat dalam Pasal 4, 17, 20, 21, 22, dan 41 Konvensi 1951.
} 
kasus penerima suaka politik di Kamboja yang ditahan selama 4 tahun harus ada peninjaun terhadap mereka yang masih diperlakukan tidak sah. ${ }^{26}$ Jika ditemukan penahanan lebih dari 4 tahun tanpa memiliki dasar yang layak akan diberikan hakhak kemerdekaan dan kebebasan yang luar biasa. Ada sejumlah pengungsi yang mendaftar masuk ke AS. Namun, setelah ada pembatasan dan pengetatan pemberian visa dari kantor keimigrasian, semua lamaran menjadi tertunda beberapa tahun. Kendatipun jaminan dari warga AS keturunan telah diberikan adanya peninjauan kembali oleh pihak imigrasi semakin mempersulit para imigran masuk ke AS.

\section{Pelanggaran Prinsip non-diskriminasi}

Bilamana memperhatikan isu kontemporer imigran dari Timur Tengah masuk ke AS, tampaknya kebijakan pembatasan pemberian visa sebagian telah melanggar HAM Internasional. Sebagaimana halnya diatur dalam Article 7, UN Charter provides that all are equal before the law and are entitled without any discrimination to the protection of the law. Seiring dengan itu, Pasal 26 ICCPR juga mengatur tentang larangan adanya diskriminasi dan menjamin untuk seluruh orang adalah sederajat dan perlindungan efektif terhadap diskriminasi segala hakhak dasar.

Diskriminasi berdasarkan agama bersumber pada kebiasaan internasional. Prinsip tersebut telah di adopsi ke dalam ICCPR dan telah dijadikan suatu kesepakatan di Majelis Umum PBB menjadi Declaration on the Elimination of All Forms of Intolerence and of Discriminations Based on Religious and Belief. ${ }^{27}$

Secara faktual, AS tergolong negara penerima pengungsi Muslim dalam periode 2016 yang wajib menerima kehadiran pengungsi. Dari 28 ribu pengungsi yang masuk ke AS dan menurut Pew Research Center dan analisis data dari Departeman Pusat Pengungsi (The State Departement's Refugees Processis Centre). AS tergolong negara yang menerima paling tertinggi pengungsi Muslim. Terjadi peningkatan 46\% hingga mendekati 85.000 pengungsi.

${ }^{26}$ Gillian D. Triggs, International Law Contemporery Principles and Practices, Lexis Nex Butterworths, 2006, hlm.

${ }^{27}$ Ibid., hlm. 908-922. 
Pertama, pelanggaran penerimaan imigran atau pengungsi Muslim telah terjadi dan bertentangan dengan asas universal "all are equal before the law". Utamanya terkait dengan diskriminasi agama dan suku. Hal ini terjadi ketika Presiden Trump melarang tujuh negara dari Timur Tengah dan Afrika yang beragama Islam. Para pengungsi tersebut, setelah diwawancarai dan diberikan penilaian lainnya pengungsi yang berkaitan dengan afilisasi agama, setelah mereka disetujui unutk diterbangkan ke AS, dan diselesaikan oleh organisasi non-profit yang bekerjasama dengan kantor-kantor penempatan pengungsi (office of refugee resettlement). Dengan rincian pengungsi meningkat 1\% hingga 10\% dari 1 juta migran yang dijamin sebagai penduduk yang sah pada setiap tahunnya.

Kedua, diskriminasi juga terlihat ketika penerimaan imigran antara Muslim dan non-Muslim berbeda. Pada 2013 dari laporan di atas, 6 berbanding 10 imigran Kristen dibandingkan dengan imigran Muslim. Utamanya jika imigran tersebut ada kaitannya sebagai korban peperangan ISIS di Irak dan Suriah. Secara keseluruhan pengungsi Kristen lebih banyak jumlahnya, utamanya yang datang dari negara-negara Afrika.

\section{Respon Masyarakat AS dan Kepedulian Pengacara terhadap Imigran Muslim}

Sebagian besar masyarakat AS telah peduli dan melawan kebijakan pelarangan imigran Muslim di AS. Mulai dari demonstrasi oleh mahasiswa di negara-negara bagian, organisasi swadaya masyarakat, dan secara khusus para ahli hukum dan pengacara. Kebijakan pelarangan atau pembatasan Muslim imigran juga mendapatkan tanggapan dari Sirin Sinnar, seorang Associate Professor di Stanford Law School, kritik atas kebijakan Presiden Donald Trump, sebelum itu George W. Bush juga tidak luput dari kritik dan protes dari ahli hukum ini. Penggunaan kekerasan dan pengiriman ke penjara Guantanamo, sebagai pelangaran atas hak-hak dasar manusia. Kebijakan tersebut telah menempatkan citra negatif George W. Bush di masyarakat Internasional. Adapun agumennya adalah bahwa pembatasan kekebasan dah hak individu bagi seseorang telah membuat Bush sebagai Presiden melakukan tindakan sewenang-wenang. Pusat Studi Konstitusi dan Hak-hak Asasi, the ACLU, menyatakan: "that civil liberties and human tights groups pushed the Bush administration to curb its wors abuses not just 
through litigation, but through more creative strategies, including advacoting with foreign government liveraging international opinion, and deploying crdedible messengare (such as generals oppose to toture) to push for policy change)." 28

Pembelaan atas praktek diskriminasi terhadap imigran Muslim, baik karena timbulnya UU Keamanan dalam Negeri. Patriot Act telah membuat kesadaran baru bagi para pengacara di AS, untuk memberikan pembelaan dan bantuan secara cuma-cuma. Atas dasar ancaman terhadap kebebasan dasar baik secara individu sebagai muslim imigran atau kelompok yang diperlakukan semena-mena untuk diselidiki oleh FBI, atau aparat kepolisian lainnya. Hampir semua aktifitas Muslim imigran, di berbagai tempat, utamanya di tempat-tempat ibadah dan Masjid tidak luput dari pengintaian dari aparat keamanan. Para pengacara memiliki komitmen tinggi atas hak-hak dasar warga AS, baik Muslim atau tidak tergerak untuk melakukan berbagai kegiatan yang membela dan melindungi para imigran Muslim.

Shirin Sinnar menyebutkan, ada empat langkah yang dilakukan para pengacara terhadap imigran Muslim yang terkena dampak, baik karena imbas media terkait terorisme 11 Setember 2001, maupun karena kebijakan Presiden Donald Trump baru-baru ini. Pertama, pengacara sangat dibutuhkan bukan hanya untuk menyebarluaskan informasi terkait keadaan imigran Muslim, tetapi juga dengan jaringan kerjasama kemitraan antar kantor pengacara lainnya. Para pengacara yang memiliki pendidikan dan profesionalitas kerja, disarankan untuk melakukan refleksi diri, mendengarkan, dan belajar secara mendalam atas peristiwa diskriminasi atas hak-hak kebebasan yang dideritas imigran Muslim di AS.

Kedua, pengacara bertugas mengetahui adanya pelanggaran terhadap HAM akan terus berlanjut dan berkembang secara sistematis. Karena itu, para pengacara harus membantu terhadap sikap politik perlawanan imigran Muslim, karena mereka sebagai warga negara. Pengacara dapat mempersiapkan suatu rencana kerjasama dengan kanor-kanot pengacara, juga para pengacara dapat mendorong aparat pemerintah kota untuk membuat peraturan-peraturan daerah, yang

${ }^{28}$ Lihat Shirin Sinnar, "Human Rights, National Security, and the Role of Lawyers in the Resistance", Stanford Civil Liberties, Civil Liberties, XIII, hlm. 37. 
melawan berbagai kebijakan pemerintah pusat terkait dengan pelanggaran HAM, pendeportasian serta batasan kerjasama dengan aparat pemerintah federal atas kepentingan keamanan dan kepentingan nasional (to help push the cities when they live to enact ordinances opposing rights infringing national security policies and limiting cooperation with federal deportation program). Para pengacara juga dapat mengorganisir kegaiatn lobi dan negosiasi dengan orang-orang disekitar, tetangga mereka untuk melakukan lobi dan negosiuasi dengan anggota-anggota Kongres, dalam memerangi kebijakan rasis' Presiden Trump.

Ketiga, para pengacara telah memberikan bantuan dengan menghadiri panggilan dari kepolisian atau aparat lainnya, baik terhadap individu karena mereka terlibat kasus, atau mereka yang sedang terancam deportasi akibat dokumen keimigrasian tidak lengkap, baik karena alasan keagamaan maupun nasionalitas atau asal usul kebangsaan. Kehadiran para pengacara juga penting dalam membnatu korban diskriminasi, karena mereka sebagai subyek yang berada dalam penahanan kepolisian Federal, Fberal Bereu Investigation, FBI. Untuk kegiatan memberikan bantuan tersebut, organisasi HAM, dan kantor-kantor pengacara telah merekrut relawan muda untuk memberikan bantuan hukum para imgran Muslim yang mendapatkan masalah akibat kebijakan pelarangan dan pembatasan imigran Muslim tinggal di AS.

Keempat, para pengacara juga telah berjuang untuk mendorong kantor-kantor pengacaranya untuk menyediakan berbagai konsultasi dengan organisasi yang bersifat tidak dipungut biaya pro-bono dan dengan meenlusuri integrtas mereka. Banyak kanor pengacara di New York, yang terlibat dalam memberkan bantuan terhadap tahananimigran Muslim di Guantanamo. Salah satu contoh, Kantor Pengacara McManis-Falkner, sebagai kantor pengacara bidang perdata di San jose, California yang telah membantu selama delapan tahun dengan biaya jutaan dollar, dengan pro-bono, membantu seorang wanita Malaysia, karena diduga terlibat dalam daftar pantauan teroris. ${ }^{29}$ Padahal daftar pemantauan terhadap seseorang warga negara itu melanggar hak-hak konstitusional. Memang pelanggar dan praktek diskriminasi telah terjadi di AS, tetapi respon dan sikap masyarakat serta

${ }^{29}$ Ibid., hlm. 45. 
orangsasi-organisasi termasuk para pengacara ikut kontribusi pada upaya memberikan bantuan atas dasar hak-hak dasar dan hak-hak kebebasan beragama dan berpendapat. ${ }^{30}$

\section{Penutup}

Sebagaimana telah diuraikan diatas dapatlah diambil kesimpulan sebagai berikut. Pertama, kebijakan Presiden Trump untuk melarang imigran Muslim dari tujuh negara di AS telah menimbulkan pro kontra warga AS, dan juga negaranegara Eropa lainnya. Karena pelarangan imigran Muslim telah menimbulkan pelanggaran Konstitusi AS. Kendatipun penerbitan the executive order sebagai wujud pelurusan kebijakan diperbolehkan, kebijakan pembatasan jauh lebih sesuai dari pelarangan dengan maksud sebagai upaya mencegah sedini mungkin serangan teroris yang dilakukan warga AS keturunan mengancam keamanan nasional dan ketenteraman warga negara. Kewajiban negara untuk melindungi warga negara AS, yaitu pembayar pajak negara, orang-orang yang terikat dengan perjanjian dalam usaha perdagangan dan perusahaan. Upaya untuk meminimalisir akibat kebijakan Presiden Trump, tetap saja berbagai pelanggaran HAM atas Pasal 30 Konvensi 1951, ICCPR, dan ICESCR 1966 telah terbukti adanya. Kajian dari Tim Mahasiswa Harvard dan Immigration Clinical Study telah mengidentifikasikan terjadinya 9 pelanggaran HAM.

Kedua, reaksi dan perlawanan atas kebijakan pelarangan imigran Muslim tidak saja datang dari warga kampus, tetapi juga dari berbagai organisasi sosial, dan lembaga-lembaga lainnya. Secara khusus, peran pengacara di hampir negaranegara bagian telah berkontribusi terhadap kebijakan perlakuan diskriminatif terhadap imigran Muslim. Peran pengacara tidak saja melakukan penyebaran informasi tentang adanya berbagai data dan fakta pelanggaran HAM, mereka juga melakukan perlindungan dan pembelaan terhadap imigran Muslim yang terkena dugaan tindakan terorisme dan kasus tanpa kepemilikan dokumen. Terakhir, peran pengacara adalah melakukan lobi dan negosiasi terhadap pemerintah dan lembaga legislatif untuk mengeluarkan peraturan daerah terkait perlindungan hak-hak dasar dan hak-hak kebebasan berpendapat dan beragama. 
Di bagian akhir tulisan ini, penulis merekomendasikan agar Pemerintah Indonesia meningkatkan hubungan diplomasi yang lebih baik agar warga negara Muslim Indonesia yang tinggal di Amerika Serikat tidak diperlakukan secara diskriminatif.

\section{Daftar Pustaka}

\section{Buku}

Evans, Malcolm (ed), International Law, Oxford University Press, 2003.

Foster, Michelle, International Refugee Law and Socio-Economic Rights, Cambridge University Press, United Kingdom, 2007.

Fuller, Graham E., A World Without Islam, Little, Brown and Company, New York Boston London, 2010.

Griffin, David Ray, The 9/11 Commission Report: Omissions And Distortions, Olive Branch Publishers, 2004.

Hathaway, James C., The Rights of Refugees Under International Law, Cambridge University Press, United Kingdom, 2005.

Lindauer, Susan, Extreme Prejudice: The Terrifying Story of the Patriot Act and the Cover Ups of 9/11 and Iraq, Create Space Independent Publishing Platform, 2010.

Selm, Joanne Van, et.al, The Refugee Convention At Fifty. A View From Forced Migration Studies, Lexington Books, United States of America, 2003.

Simeon, James C., Critical Issues in International Refugee Law. Strategies Toward Interpretative Harmony, Cambridge University Press, United Kingdom, 2010.

Steiner, Henry J., Phillip Alston, and Ryan Goodman, International Human Rights in Context: Law, Politics, Morals: Text and Materials, Oxford University Press, 2008.

Thontowi, Jawahir, Terorisme Negara. Kerjasama Konspiratif Menjinakkan Islam Fundamentalis, UII Press, Yogyakarta, 2013.

Triggs, Gillian D., International Law Contemporery Principles and Practices, Lexis Nex Butterworths, 2006.

Wagiman, Hukum Pengungsi Internasional, Sinar Grafika, Jakarta, 2012.

William, Emerson, Encyclopedia Of United States Army In Sign An Uniforms, University of Oklahoma Press, 1996.

\section{Jurnal dan Karya Ilmiah}

Al Wekhian, Jamil, "Acculturation Process of Arab-Muslim Immigrant in the United States", Canadian Center of Science and Education, Asian Culture and History, Vol. 8, No 1, 2016. 
Hwang, Brandon and Kyle Pang, "An Era of Islamophobia: The Muslim Immigrant Experience in America", Pepperdine Journal of Communication Research, Vol. 5, Article 11, 2017.

Kajian Tim Mahasiswa Harvard Law School, “The Impact of President Trump's Executive Order on Asylum Seeker", Harvard Immigration and Refugee Clinical Program, 2016.

Laporan Homeland Security Committee, "Syrian Refugee Flows. Security Risk and Counterterrorism Challenges" Preliminary Findings of a House Homeland Security Committee Review, November, 2015.

Sinnar, Shirin, "Human Rights, National Security, and the Role of Lawyers in the Resistance", Standford J. Of Civil Rights E Civil Liberties, Vol. XIII, No. SE37, 2017.

Thontowi, Jawahir, "The Islamic Perspective of the War on Terrorism and Current Indonesian Responses", Makalah Seminar Internasional the Human Rights 2003: The Year in Review, diselenggarakan oleh the Castan Centre for Human Rights Law, Monash Law School, 2003.

\section{Instrumen Hukum}

Executive Order, The White House Washington. Protecting the Nation From Terrorist Attacks by Foreign Nationals, 2017.

Konvensi Pengungsi 1951

Memorandum for The President dalam Dokumen resmi, The White House, Washington, 23 Januari 2017.

\section{Website}

http:/ / www.allied.media.com diakses pada tanggal 23 Maret 2017

http:/ / www.pewresearch.org/fact-tank/2016/01/06/a-new-estimate-of-the-u-smuslim-population/ diakses pada 23 Maret 2017

http:/ / www.tmn.today/2016/10/pope-benedict-xvi-forbid-catholics-votinghillary/ diakses pada 23 Maret 2017.

https:/ /en.wikipedia.org/wiki/List_of_illegal_political_parties_in_Turkey diakses pada tanggal 23 Maret 2017

https:/ / www.donaldjtrump.com/ press-releases/donald-j.-trump-statement-onpreventing-muslim-immigration diakses pada tanggal 23 Maret 2018

https:/ / www.whitehouse.gov/the-press-office/2017/01/27/executive-orderprotecting-nation-foreign-terrorist-entry-united-states diakses pada tanggal 27 Maret 2017

Justin O Smith, The Muslim U.S. Military Experience, dalam www.danielpipes.org/comments/197390 diakses pada tanggal 27 Maret 2017 